\title{
IDENTIFIKASI KENDALA PENGELOLAAN KAWASAN AGROPOLITAN KABUPATEN CIANJUR
}

\author{
GIZDY CHALIFA CHAIRUL RIZALDI*, NUR SYAMSIYAH \\ Program Studi Agribisnis, Fakultas Pertanian, Universitas Padjadjaran \\ *Email: gizdyc@gmail.com
}

\begin{abstract}
ABSTRAK
Urbanisasi merupakan salah satu permasalahan utama di Indonesia. Laju urbanisasi di Indonesia naik 3,3\% setiap tahun dan angka ini merupakan laju urbanisasi tercepat se-Asia. Urbanisasi memberikan pengaruh positif dan negatif. Salah satu dampak negatif yang ditimbulkan oleh urbanisasi adalah kurangnya regenerasi petani karena urbanisasi dan migrasi merupakan salah satu alasan terjadi kurangnya regenerasi petani khususnya di wilayah pedesaan. Program agropolitan merupakan salah satu solusi yang dilakukan pemerintah untuk menekan angka urbanisasi tersebut sejak tahun 2002. Kawasan Agropolitan Kabupaten Cianjur merupakan salah satu kawasan agropolitan yang pertama kali dibentuk pada tahun 2002. Setelah berjalan 16 tahun, kawasan agropolitan ini tidak berkembang secara signifikan. Tujuan dari penelitian ini adalah untuk mengidentifikasi kendala pengelolaan Kawasan Agropolitan Kabupaten Cianjur agar para stakeholder bisa menemukan solusi dari kendala tersebut. Identifikasi kendala pengelolaan menggunakan metode analisis deskriptif. Data didapatkan dari hasil wawancara dengan stakeholder kawasan agropolitan. Kendala yang dihadapi yaitu benih komoditas tertentu terkadang sulit didapatkan, gangguan hama penyakit dan pencurian, penggunaan bahan kimia yang masih tinggi, kurangnya pengetahuan petani akan pengolahaan produk yang tidak sesuai permintaan (reject), fasilitas packing house yang terlalu jauh, pasar produk olahan yang sedikit, kurangnya pertemuan antar stakeholder kawasan agropolitan, petani belum mengerti sistem kawasan agropolitan, kurangnya monitoring dan evaluasi dari pemerintah, sarana dan prasarana yang rusak.
\end{abstract}

Kata kunci: Kendala, agropolitan, Kabupaten Cianjur

\section{ABSTRACT}

Urbanization is one of main problem in Indonesia. Indonesia's rate of urbanization is increase 3,3\%/year and it is the fastest urbanization rate increase in Asia. Urbanization will give positive and negatve influence. One of the negative influence is urbanization will caused the lack of farmers regeneration because urbanization and migration is one of main reason the lack of farmers regeneration in rural area. Agropolitan program is one of solution that implemented by government to pressing the urbanization number since 2002. Cianjur Agropolitan Area is one of agropolitan area which is included into 8 first agropolitan area that established by government. After 16 years running, Cianjur agropolitan area did not grow significantly. The aim of this research is to identify management's obstacles. This research use descriptive analyze method. Data obtained from the interview process with agropolitan's stakeholder. Management's obstacles that faced by Cianjur Agropolitan Area are seeds of certain commodities sometimes it is difficult to get, interference of pest and theft, high chemical usage, lack of farmers knowledge about processing reject product, packing house is too far, lack of processed product's market, fewer meetings of agropolitan's stakeholder, farmers have yet to completely understand about agropolitan area's system, lack of monitoring and evaluation process from the government, some facilities and infrastructure is broken.

Keyword: management's obstacles, agropolitan area, Cianjur's Agropolitan Area, descriptive analysis 


\section{PENDAHULUAN}

Pengertian urbanisasi dapat ditinjau dari beberapa ilmu pengetahuan. Secara demografi, urbanisasi adalah suatu proses yang ditunjukkan melalui perubahan penyebaran penduduk dan jumlah penduduk yang ada dalam satu wilayah (berakibat pada masalah pangan, pemukiman, dan pekerjaan). Dari segi ekonomi, urbanisasi adalah perubahan struktural dalam sektor mata pencaharian (adanya peralihan pekerjaan dari agraris ke non agraris). Secara sosiologis, urbanisasi dikaitkan dengan sikap hidup penduduk dalam lingkungan pedesaan yang mendapat pengarus dari kehidupan kita atau bisa disebut pengotaan (Muryanti, 2012).

World Bank (2016) melansir laju urbanisasi atau perpindahan penduduk dari desa ke kota di Indonesia merupakan tercepat di Asia. Selama 60 tahun, populasi perkotaan di Indonesia meningkat rata-rata 4,4 persen. Diprediksi dalam 10 tahun mendatang, sekitar $68 \%$ penduduk Indonesia berada di wilayah perkotaan. "Indonesia negara urbanisasi tercepat di Asia. Rasio urbannya lebih cepat dari China dan India. 177 juta orang tinggal di perkotaan", ujar Ketua Program City Planning Labs dari World Bank.

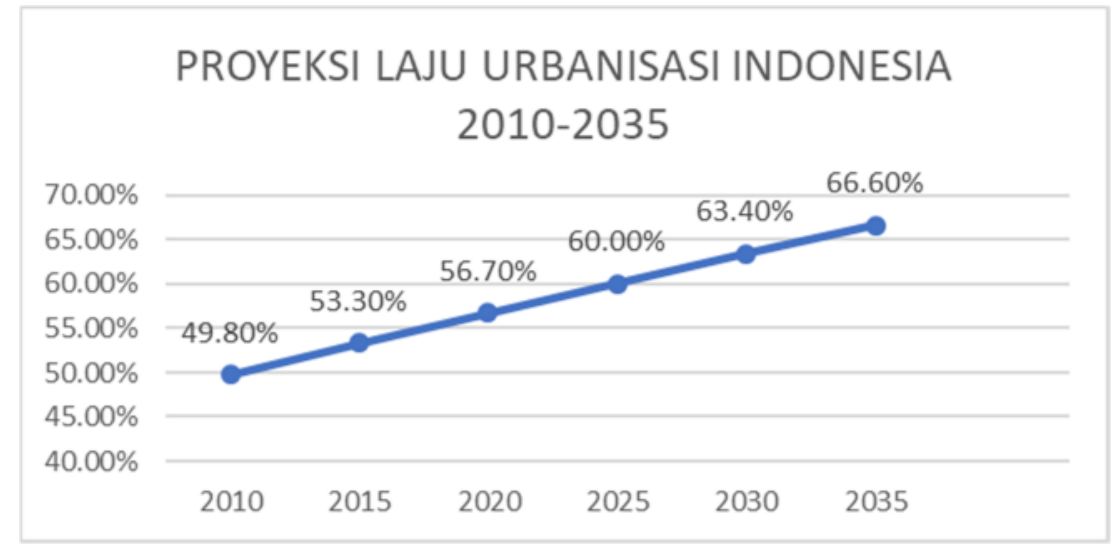

Gambar 1. Grafik Proyeksi Laju Urbanisasi Indonesia 2010-2035

Sumber: Indonesia Population Projection 2010 - 2035 (2013), BPS- Bappenas-UNFPA

Berdasarkan Gambar 1 dapat dilihat bahwa laju urbanisasi Indonesia akan terus meningkat dengan peningkatan rata-rata $3,3 \%$ tiap tahunnya. Artinya, pada tahun 2035 sebesar $66,60 \%$ penduduk Indonesia akan berada di wilayah perkotaan. Wilayah perdesaan masih memiliki banyak potensi sumberdaya alam dan juga sumberdaya manusia yang dapat dimanfaatkan dan dikembangkan. Dan apabila potensi tersebut 
dapat dikelola secara baik, masyarakat pun akan memilih bertahan di desa untuk bekerja demi meningkatkan taraf hidup dan kesejahteraanya. Tingkat urbanisasi dan tempo urbanisasi per provinsi di Indonesia tahun 2000-2010 ${ }^{1}$ menunjukkan hampir seluruh wilayah di Indonesia mengalami kenaikan tempo urbanisasi kecuali provinsi Riau dan Maluku Utara. Data tersebut menunjukkan bahwa Provinsi Jawa Barat merupakan provinsi dengan tempo urbanisasi paling besar di antara provinsi lain di Indonesia dengan tempo urbanisasi sebesar 1,54 sejak tahun 2000-2010. Tempo urbanisasi adalah selisih persentase penduduk perkotaan dibagi dengan rentang waktu yang ada. Tempo urbanisasi memberikan gambaran tentang cepat lambatnya tingkat urbanisasi.

Menurut Swastika (2014), untuk mengatasi ketimpangan yang meyebabkan urbanisasi, maka harus ada keseimbangan pembangunan antara perdesaan dan perkotaan. Perdesaan harus diurbanisasi dalam paradigma lain, yaitu di-kota-kan, atau dijadikan desa maju dengan fasilitas infrastruktur perkotaan. Pedesaan harus dibangun secara terpadu, mulai dari rehabilitasi dan pembangunan infrastruktur pertanian, reorientasi industri berbasis pertanian dari perkotaan ke perdesaan, sampai pembangunan infrastruktur untuk mendukung aktivitas sosial ekonomi. Dengan demikian, diharapkan perdesaan bisa tumbuh secara mandiri, dinamis dan sejahtera, sehingga menjadi tempat tinggal yang menarik bagi masyarakat desa dan tidak perlu pindah ke kota mencari pekerjaan.

Menurut Friedman dan Douglas (1976) dalam Ma'mun, dkk, konsep agropolitan merupakan strategi pembangunan yang dipercepat dengan memperkenalkan unsur gaya hidup (manajemen) kota yang dsesuaikan dengan lingkungan dan budaya pedesaan (internalized) sehingga mendorong masyarakat desa untuk produktif dan tetap tinggal di perdesaan, mengurangi migrasi, mengurangi keretakan sosial (social dislocation) dalam proses pembangunan, serta membangun jaringan (networking) dengan sektor lain sehingga terbentuk ruang

\footnotetext{
${ }^{1}$ Tabel Tingkat Urbanisasi Dan Tempo Urbanisasi Provinsi-Provinsi Di Indonesia Tahun 2000-2010. BPS RI (2010)
} 
sosio-tekno-ekonomis dan politik yang lebih luas.

Menurut Idrus (2012), konsep agropolitan diterapkan pemerintah sejak tahun 2002. Pada awalnya hanya diterapkan di 8 provinsi, yaitu Sumatera Barat, Bengkulu, Jawa Barat, D.I Yogyakarta, Bali, Sulawesi Selatan, Gorontalo, Kalimantan Timur. Namun, pada tahun 2003 diperluas mencakup 29 provisnis di luar DKI Jakarta.

Tabel 1. Kawasan Agropolitan yang Direncanakan pada Tahun 2002

\begin{tabular}{ll}
\hline Provinsi & Kawasan Agropolitan \\
\hline Sumatera Barat & Kabupaten Agam \\
Bengkulu & Kabupaten Rejang Lebong \\
Jawa Barat & Kabupaten Cianjur \\
D.I. Yogyakarta & Kabupaten Kulonprogo \\
Bali & Kabupaten Bali \\
Sulawesi Selatan & Kabupaten Barru \\
Gorontalo & Kabupaetn Boalemo \\
Kalimantan Timur & Kabupaten Kutai Timur \\
\hline Sumber: Idrus, Amwazi. 2012. Agropolitan dan \\
\multicolumn{2}{c}{ Minapolitan } \\
\multicolumn{2}{c}{ keharmonsan". Jakarta: Kementerian Cipta } \\
Karya dan Tata Ruang
\end{tabular}

Pada tahun 2002 pemerintah Indonesia berencana untuk membentuk kurang lebih 8 kawasan agropolitan yang tersebar di seluruh Indonesia. Tahap ini merupakan tahap awal pembentukan yang diawali oleh adanya pelatihan beberapa petani calon pengurus agropolitan. Di Pulau Jawa sendiri terdapat 2 provinsi yang menjadi sasaran program kawasan agropolitan ini, yaitu Provinsi Jawa Barat dan D.I. Yogyakarta. Kabupaten Cianjur di
Provinsi Jawa Barat dan Kabupaten Kulon Progo di Provinsi D.I. Yogyakarta untuk pengembangan kawasan agropolitan.

Kawasan Agropolitan di Kabupaten Cianjur memiliki Desa Pusat Pertumbuhan yaitu Desa Sukatani di Kecamatan Pacet dan Desa Sindangjaya di Kecamatan Cipanas. Pengembangan ini pun tercantum dalam Perda Kabupaten Cianjur No. 17 Tahun 2012 tentang Rencana Tata Ruang Wilayah Kabupaten Cianjur. Kecamatan Cipanas dan Kecamatan Pacet merupakan wilayah pusat pertanian khususnya sayuran di Kabupaten Cianjur. Daerah ini merupakan salah satu pemasok komoditas hortikultura untuk wilayah JABODETABEK dan merupakan tujuan wisata turis domestic. Karena menjadi salah satu tujuan wisata, yang menyebabkan alih fungsi lahan di daerah tersebut dari lahan pertanian menjadi perumahan untuk warga maupun untuk villa.

Kawasan Agropolitan Cianjur sudah berjalan kurang lebih 15 tahun saat ini tidak aktif dikelola. Padahal sejak selesai dibangun pada tahun 2006 kawasan agropolitan memberikan dampak poisitif pada wilayah setempat karena infrastruktur jalan dibangun, dan sarana prasarana produksi seperti packing house, wisma 
untuk agrowisata, gedung untuk P4S, dengan tujuan untuk mendorong Kawasan Agropolitan Cianjur berjalan secara maksimal. Karena saat ini pengelolaan sedang tidak dilakukan dengan baik, maka semua fasilitas saat ini kondisinya kurang baik contohnya jalan sudah mulai rusak dan juga sarana dan prasarana sudah tidak dimanfaatkan secara optimal.

Berdasarkan latar belakang di atas maka identifikasi masalah dari penjelasan di atas adalah mengidentfikasi kendala pengelolaan kawasan agropolitan. Tujuan yang hendak dicapai oleh penelitian ini ialah mengetahui kendala pengelolaan kawasan agropolitan Kabupaten Cianjur.

\section{METODE PENELITIAN}

Desain penelitian yang digunakan ialah metode kualitatif dengan teknik studi kasus. Data yang digunakan merupakan data primer dan sekunder. Data primer diperoleh dari hasil observasi, wawancara, dan pengisian kuesioner. Sedangkan data sekunder diperoleh dari data pengurus kawasan agropolitan, data desa, penelitian terdahulu, dan berbagai literatur yang relevan dan dapat mendukung topik penelitian. Penentuan informan dilakukan melalui purposive sampling.
HASIL DAN PEMBAHASAN

Kendala dalam Proses Produksi

\section{a. Bibit komoditas tertentu terkadang sulit didapatkan}

Menurut petani, akses terhadap input pertanian cukup mudah dijangkau karena jaraknya yang dekat. Kerjasama yang dijalin pun cukup baik dan saling menguntungkan. Input berupa pupuk dan bahan pencegah atau pembasmi hama mudah didapatkan. Persediannya pun relatif selalu aman karena petani setiap saat bisa mengakses semua dengan mudah. Akan tetapi untuk input berupa bibit terkadang susah diakses oleh petani. Tak jarang bibit yang sulit dicari itu merupakan bibit komoditas eksklusif seperti brokoli. Para responden petani menuturkan bahwa saat mereka bertanya pada pedagang produk pertanian, para pedagang menyebutkan bahwa bibit tersebut persediannya sedang kosong. Selang beberapa hari setelah pedagang menuturkan kosong, bibit yang persediannya kosong tersebut beredar kembali namun dengan harga yang jauh lebih tinggi dibanding sebelumnya. Ini menjadi kendala bagi petani, di saat petani ingin memproduksi sayuran yang harganya sedang baik, bibit tanaman yang dimaksud 
tidak ada sehingga petani harus mencari tanaman lain yang bibitnya tersedia.

\section{b. Gangguan hama penyakit dan pencurian komoditas}

Petani berpendapat bahwa serangan hama merupakan kondisi yang wajar yang dihadapi oleh setiap petani. Penanganan pada saat awal tanam dan musim berpengaruh besar terhadap kondisi ini. Menurut petani, hama dan penyakit bisa di atas dengan menggunakan obat-obatan baik organik maupun kimia. Pencurian terhadap komoditas merupakan kendala serius yang dihadapi oleh petani. Setiap akan panen terutama komoditas yang harganya sedang mahal, tak jarang petani menemukan tanaman hasil budidayanya diambil oleh pencuri. Beberapa petani yang pernah mengalami kejadian ini bahkan pernah mengalami kerugian hampir 90\%, karena hampir seluruh tanamannya sudah dipanen terlebih dahulu oleh para pencuri. Para petani mencegah terjadinya pencurian ini dengan cara melakukan ronda malam di kebun masing-masing sambil sesekali menyorotkan senter pada kebun mereka.

Beberapa petani menilai cara ini kurang efektif karena di beberapa kasus para pencuri mengambil sayur saat petani petani shalat shubuh atau istirahat sebentar.
Namun saat ini kegiatan pencurian relatif berkurang karena sudah ada beberapa pencuri yang ditangkap dan diberikan kepada pihak yang berwajib.

\section{c. Penggunaan bahan kimia yang masih tinggi}

Menurut penyuluh lapangan, input kimia yang digunakan masih cukup tinggi di kawasan agropolitan walaupun ada beberapa petani yang sudah menyesuaikan input kimia dengan kebutuhan dan masih dapat dikontrol. Menurut penyuluh pendamping lapangan, hal ini menjadi kendala karena beberapa pasar khususnya pasar supermarket menginginkan produk sayuran yang organik atau setidaknya telah dinilai aman pangan oleh dinas pertanian. Sosialisasi mengenai penggunaan bahan organik terus dilakukan penyuluh dengan harapan petani mengontrol asupan kimianya.

\section{Kendala dalam Proses Pascapanen}

\section{a. Kurangnya pengetahuan petani akan pengolahaan produk yang tidak sesuai permintaan (reject)}

Menurut pihak desa, petani di kawasan agropolitan masih terkendala dengan sayuran yang tidak sesuai dengan permintaan pasar atau kondsinya kurang baik (reject). Untuk mengatasi hal itu 
beberapa petani mengonsumsi sendiri sayur reject yang kondisinya masih layak konsumsi. Namun untuk yang sudah busuk, para petani sebagian besar membuang sayur tersebut ke arah kali dekat jembatan perbatasan antara Sukatani dan Sindangjaya. Belum semua petani bisa mengolah sampah tadi menjadi pupuk kompos. Menurut Murbandono dalam Syaifudin (2013), Pengolahan limbah padat ini perlu dilakukan salah satunya dengan menjadi pupuk kompos. Pupuk kompos ini akan memberikan 3 keuntungan, yaitu: dapat mengurungai limbah padat sayuran. Untuk tanah kompos dapat menambah unsur hara dan memperbaiki struktur dan tekstur tanah. Dengan kualitas tanah yang semakin baik maka produksi tanaman akan optimal. Saat ini sudah ada pengolahan sayur reject khususnya sayuran daun. Terdapat perusahaan rumahan yang menggunakan fasilitas packing house untuk menjadi pabrik tahu. Tahu ini merupakan campuran antara bahan tahu dengan sayur yang reject. Perbandingannya yaitu $3 \mathrm{~kg}$ bahan tahu dicampur $1 \mathrm{~kg}$ sayuran. Namun saat ini pabrik tahu tersebut sudah tidak berjalan lagi padahal belum genap 3 bulan berjalan.

\section{b. Fasilitas packing house yang dinilai terlalu jauh oleh petani}

Menurut para petani responden yang jarak kebunnya cukup jauh dari pusat agropolitan, jarak antara kebun dengan packing house dinilai cukup jauh. Apabila memang mereka harus melakukan kegiatan packaging di packing house, biaya yang mereka akan keluarkan tentu akan bertambah. Fasilitas di packing house pun belum memadai menurut petani. Apabila ada 50 petani akan melakukan kegiatan packaging maka akan berdesakan dan waktu yang dibutuhkan semakin lama. Sehingga para petani memilih untuk melakukan proses pascapanen di rumah masing-masing karena mereka nilai yang paling efektif. Menurut Pak Enan selaku Kabag Perencanaan Dinas Pertanian Perkebunan Pangan Hortikultura Kabupaten Cianjur, sudah ada bantuan pemerintah untuk membantu petani dalam hal ini yaitu pemerintah membantu membangun tempat pencucian sayuran di beberapa rumah petani.

\section{c. Pasar produk olahan yang kurang}

Di DPP Kawasan Agropolitan terdapat KWT yang mengolah hasil komoditas yang tidak masuk ke pasar. Mereka mengolahnya menjadi keripik, selai 
tomat, dan olahan lainnya. Namun mereka kesulitan untuk mengakses pasar karena terhambat oleh produk mereka yang belum memiliki PIRT atau sertifikat BPOM. Produk yang mereka jual pun masih dinilai mahal karena teknologi yang mereka gunakan masih sederhana dan belum mencapai tingkat produksi yang efisien. Sehingga mereka memutuskan untuk berhenti mengolah.

\section{Kendala Dalam Proses Pengelolaan} Kawasan Agropolitan

\section{a. Kurangnya pertemuan antar stakeholder kawasan agropolitan}

Menurut keyperson, memang sudah lama tidak ada pertemuan antar stakeholder yang bergerak di kawasan agropolitan. Semenjak POKJA berhenti bekerja pada tahun 2012, integrasi antar pihak dinilai kurang oleh para keyperson. Pertemuan diadakan apabila ada keperluan dan apabila ada kesempatan. Pertemuan yang terjadwal satu bulan sekali sudah lama tidak dilakukan. Hal ini berakibat kepada proses pengelolaan agropolitan yang kurang jelas. Oleh karena itu biaya pemeliharaan untuk perawatan infrastruktur khususnya perawatan gedung dibebankan ke pengurus. Para pengurus merasa keberatan dengan hal ini karena dalam satu bulan mereka harus mengeluarkan biaya sekitar Rp 600.000 untuk membayar biaya listrik. Kurangnya koordinasi ini juga menyebabkan miss communication diantara stakeholder. Program yang masih aktif di kawasan agropolitan saat ini hanya P4S. P4S menggunakan sumber dana swadaya, tidak ada bantuan insentif dari pemerintah. Banyak kegiatan penelitian dan permagangan yang memanfaatkan $\mathrm{P} 4 \mathrm{~S}$ Agropolitan Kabupaten Cianjur. Instansi yang menggunakan P4S Agropolitan Kabupaten Cianjur seperti IPB, UNPAD, UNBRAW, UNSUR, LIPI, dan pemerintah daerah yang ingin mengadakan studi banding.

\section{b. Petani belum sepenuhnya mengerti bagaimana sistem kawasan agropolitan}

Responden petani menuturkan mereka belum sepenuhnya mengerti tentang sistem kawasan agropolitan. Mereka pun tidak mengetahui mengenai sistem agropolitan, sehingga mereka seperti tidak ingin tahu tentang kawasan agropolitan dan hanya fokus pada usahatani mereka tanpa ada keinginan untuk mengembangkan kawasan agropolitan. Petani mengemukakan bahwa ada dampak positif 
yang dirasakan di kawasan agropolitan seperti jalan lebih baik dari sebelumnya dan terdapat jalan menuju kebun.

\section{c. Kurangnya monitoring dan evaluasi dari pemerintah}

Menurut Mahardhani (2012), program agropolitan sejatinya dinyatakan berhasil apabila memenuhi 3 indikator, yaitu: pembangunan sarana dan prasarana, peningkatan sistem dan usaha agribisnis, dan pengembangan mutu dari sumberdaya manusia perdesaan. Pengelola kawasan agropolitan dan petani mengharapkan pemerintah terus melakukan monitoring dan evaluasi dan mengecek indikator yang telah ditetapkan oleh pemerintah pusat atau daerah. Pemerintah butuh melakukan monitoring dan evaluasi secara berkala untuk menilai kemajuan kawasan agropolitan. Untuk mengatasi hal ini pemerintah sudah membentuk sebuah UPTD. UPTD STA dan Agropolitan ini pada dasarnya untuk kembali membangun kawasan agropolitan menggantikan POKJA yang telah bubar pada tahun 2012. UPTD ini berada di bawah koordinasi Dinas Pertanian Pangan Perkebunan Hortikultura Kabupaten Cianjur. Anggota UPTD ini seluruhnya merupakan pegawai Dinas Pertanian Pangan Perkebunan Hortikultura
Kabupaten Cianjur. Menurut Ibu Inna selaku Kasubag Bidang Usahatani Dinas Pertanian Pangan Perkebunan Hortikultura Kabupaten Cianjur, UPTD ini bertujuan untuk mengembangkan kembali kawasan agropolitan. Saat ini dinas pertanian merencanakan beberapa program untuk membangun kawasan agropolitan, salah satunya dengan perencanaan pembangunan green house di DPP Kawasan Agropolitan seluas $600 \mathrm{~m} 2$. Diharapkan dengan adanya green house ini bisa menjadi sumber pengetahuan petani terutama pengetahuan budidaya tanaman eksklusif seperti paprika dan tomat beef.

\section{d. Sarana dan prasarana yang rusak}

Jalan menuju kawasan aropolitan sudah banyak yang rusak terutama di Kampung Gunung Batu dan wilayah Pasir Kampung. Hal ini mengakibatkan terganggunya proses distribusi. Petani berpendapat bahwa banyak sayuran yang dikhawatirkan rusak apabila melalui jalan tersebut. Keyperson menilai ini adalah masalah yang harus terlebih dahulu diselesaikan karena berpengaruh langsung kepada pendapatan petani. Biaya kirim sayuran menjadi meningkat karena hal ini. Gedung sekretariat dan packing house sudah dalam kondisi yang kurang baik. Hal 
ini ditandai dengan bocornya atap, kursi yang rusak, cat yang sudah mengelupas, jendela yang rusak. Pengurus tidak mampu memperbaiki ini karena keterbatasan biaya.

\section{KESIMPULAN DAN SARAN}

Kendala yang dihadapi dalam proses pengelolaan Kawasan Agropolitan Kabupaten Cianjur yaitu beberapa bibit komoditas tertentu terkadang sulit didapatkan, gangguan hama penyakit terutama manusia, penggunaan bahan kimia yang masih tinggi, kurangnya pengetahuan petani akan pengolahaan produk yang tidak sesuai permintaan (reject), fasilitas packing house yang dinilai terlalu jauh oleh petani, pasar produk olahan yang kurang, kurangnya pertemuan antar stakeholder kawasan agropolitan, petani belum sepenuhnya mengerti bagaimana sistem kawasan agropolitan, kurangnya monitoring dan evaluasi dari pemerintah, sarana dan prasarana yang rusak.

\section{DAFTAR PUSTAKA}

Ma'mun, Deddy, dkk. 2013. Arahan Struktur Tata Ruang Kawasan Agropolitan Kecamatan Baros Kabupaten Serang Provinsi Banten. Ambon: Jurnal Agroogia Universitas Pattimura
Detik Finance. 2016. Bank Dunia: Laju Urbanisasi di RI Lebih Cepat dari China dan India. Jakarta: https://finance.detik.com/ekonomibisnis/3286873/bank-dunia-lajuurbanisasi-di-ri-lebih-cepat-darichina-dan-india (diakses tanggal 1 April 2017)

Idrus, Amwazi. 2012. AGROPOLITAN \& MINAPOLITAN Konsep Kawasan Menuju Keharmonian. Jakarta : Kementrian Pekerjaan Umum

Mahardhani, Ardhana Januar. 2012. Implementasi Kebijakan Pengembangan Kawasan AGropolitan Sendang Kabupaten Tulungagung. Surbaya: Universitas Airlangga

Muryanti. 2012. Perempuan Pedesaan (Kajian Sosiologis Pekerja Rumah Tangga/PRT). Yogyakarta: Bima Sakti Publishing

Swastika, DK. 2014. Reformasi Paradigma Urbanisasi: Strategi Percepatan Pengentasan Kemiskinan di Perdesaan. DKI Jakarta: Badan Penelitian dan Pengembangan Kementrian Pertanian Indonesia Syaifudin, Nur Luqman.2013.Pemanfaatan Limbah Sayur-Sayuran untuk Pembuatan Kompos dengan Penambahan Air Kelapa (Cocos nucifera) dan Ampas Teh Sebagai Pengganti Pupuk Kimia Pada Pertumbuhan Tanaman Semangka (Citrullus vulgaris L). Surakarta: Universitas Muhammadiyah Surakarta 